\title{
Flexible Financing and Investment in Renewable Energy Sources: The Case of Biogas Energy in Sidama Region, Ethiopia
}

\author{
Tarekegn Mamo Legamo, ${ }^{1,2}$ \\ ${ }^{1}$ Department of Economics, Hawassa University, Hawassa City, Ethiopia \\ ${ }^{2}$ Faculty of Humanities, Charles University PhD Environmental Studies Programme, Prague City, Czech Republic
}

Email address:

tarleg2013@gmail.com

\section{To cite this article:}

Tarekegn Mamo Legamo. Flexible Financing and Investment in Renewable Energy Sources: The Case of Biogas Energy in Sidama Region, Ethiopia. American Journal of Environmental and Resource Economics. Vol. 5, No. 4, 2020, pp. 86-96. doi: 10.11648/j.ajere.20200504.12

Received: October 22, 2020; Accepted: November 3, 2020; Published: November 9, 2020

\begin{abstract}
In attempt to meeting energy demand via provision of renewable energies such as biogas technology, credit arrangements and local involvement in decision-making are key elements for low-income countries in Africa, while the link between investment cost, affordability, financing, and other socioeconomic differences may affect investment in biogas energy. In this article, a survey of 298 households is used to establish the derivers of investment in biogas energy; the findings being conditioned on credit access with flexible loan repayment options. The estimates of marginal effects from conditional (multinomial) logit model show that flexible loan repayment options might encourage a broader spectrum of households to invest in biogas energy. The key derivers of willingness to invest in short-term loan repayment options were the education and gender of household heads, access to fuelwood sources and waste-water systems, and, livestock ownership. Similarly, households' willingness to invest in biogas energy funded via medium term financing varies with the level of formal education of household heads, wastewater system, and livestock ownership. However, willingness to fund biogas energy with long-term loans was positively correlated with the area of land in use. Policy implications are that local authorities should work with financial institutions to provide credit at market rates, but with flexible loan repayment options. This will reduce the burden of the biogas market on both users and supplier's, increase functional sustainability, and promote biogas technology among low-income communities.
\end{abstract}

Keywords: Biogas Energy, Determinants, Investment Decision, Flexible Financing, Ethiopia

\section{Introduction}

Extensive reliance on biomass as an energy source is common in Sub-Saharan Africa, where fuelwood is the dominant source of energy. In Africa, including Ethiopia, about 90 percent of rural households are dependent on fuelwood for open fire cooking and lighting despite its poor energy efficiency and high negative impact on the environment [1]. Currently, affordable and clean energy services is one of the key challenges of low-income countries, and most of their populations are living in energy poverty [2].

Energy supply and demand systems have many implications for the livelihood of households, indoor environmental pollution, socio-economic outcomes and local climate change in Africa [3]. However, in attempt to meet increasing energy demand via provision of clean energy sources, credit arrangements, and local involvement in decision-making are key elements for low-income countries in Africa, while the link between investment cost, affordability, financing, and other socioeconomic differences may affect investment in biogas energy [4]. Specifically, finding new approach which may increase access to renewable energies at affordable and lower transaction costs required an effort and wise choice to mitigate the risks of indoor pollution and the resulting socioeconomic and health impacts [5].

Biogas energy technology provides low-income households with clean cooking and lighting fuel and bio-slurry fertilizer in Africa, including Ethiopia. It also benefits women and children by reducing the negative socio-economic burden (health, education, and environment) associated with traditional biomass use in Africa, where women are primarily responsible for cooking and fuel collection $[6,7]$. 
Despite the numerous benefits of biogas, household investment in biogas energy is restricted by several factors. Economic factors are the major determinants of use and commercialization of biogas energy across low-income households in Africa. These factors include cost of material supply, land, labor, plant size, location, technology, and the substitutability benefits of other fuel sources [8]. Institutional factors also are important: Functioning and sustainable institutions with systematic marketing and commercialization strategies are important for investing in biogas energy in low-income countries [9].

Biogas energy technology was introduced in Ethiopia in the late 1970's. However, the development of biogas energy is very slow. For example, until 2007/2008, only 200 biogas energy plants were constructed across the country. In order to speed up its outreach, in 2007, the Netherlands development organization (SNV) assisted with a program to promote biogas technology on a national scale [10]. Though this was a 5-year project to construct 14,000 biogas plants in rural and urban areas in the country, only 8,000 biogas plants were successfully developed during the project period. Currently, few biogas plants are being generated from cattle dung because several biogas energy plants are non-functional. The Netherlands Development Organization report shows $40 \%$ of constructed biogas plants were non-functional, and earned a bad reputation for biogas energy technology among some user communities [5]. For example, in Sidama and Southern Nations, Nationalities and People's Regions a recent biogas plant inventory report revealed only $40 \%$ of the 3,345 biogas energy plants constructed between 2008 and 2016 were operating [11]. The inventory report finds reasons for non-functionality of biogas plants to be ineffective management, poor follow-up, technical complications, lack of interest in ownership, and reductions in animal holdings.

The key question is how to achieve sustainable and affordable biogas energy aligned with sustainable and flexible financing mechanisms. This requires investigating key factors driving investment in renewable energies by low-income households to assist with policy design. In this study, the main research questions are: Does access to credit help households get biogas energy? Does the term (duration) of loan repayment schedule matter? What other factors determine investment in small-scale biogas technology in suburban and urban areas?

This article analyses household investment decision in biogas energy conditioned on credit access at flexible loan repayment options. To estimate factors deriving investment decision related to biogas energy at given three loan repayment options for a given household, we use a multinomial logit model.

\section{Related Literature}

\subsection{Affordability of Biogas Technology in Low-income Countries}

Establishing affordable clean energy services is one of the key challenges of low-income countries, where the majority of people live in energy poverty [2]. Low levels of clean energy use and energy poverty are directly associated with energy demand and supply scarcity. In the demand side, the poor cannot afford modern fuels because of their low purchasing power relative to the cost of the fuels. The supply scarcity is characterized by low electricity generation capacity, shortages of foreign exchange, inefficient service provision, imperfections in energy markets and lack of infrastructure [12].

Affordability related to investment costs required to develop biogas plants show heterogeneity across continents, specifically in Africa and Asia, where the majority of the population live in low income categories and are involved in subsistent occupations such as small-scale farming. According to the SNV assessment report (2014), the average investment cost in Africa is more expensive than in Asian countries. The following table presents initial investment cost, per capita GDP share, and year of construction in selected African countries.

Table 1. Investment cost, per capita GDP share and year.

\begin{tabular}{lllll}
\hline \multirow{2}{*}{ Country } & \multicolumn{2}{l}{$\begin{array}{l}\text { Initial investment cost } \\
\text { (EUR) }\end{array}$} & $\begin{array}{l}\text { Per capita GDP share } \\
\text { (\%) }\end{array}$ \\
\cline { 2 - 5 } & Year 2012 & Year 2013 & Year 2012 & Year 2013 \\
\hline Ethiopia & 400 & 350 & $65 \%$ & $45 \%$ \\
Kenya & 500 & 530 & $52 \%$ & $45 \%$ \\
Rwanda & 963 & 673 & $83 \%$ & $53 \%$ \\
Uganda & 588 & 535 & $53 \%$ & $49 \%$ \\
Tanzania & 250 & 400 & $45 \%$ & $39 \%$ \\
Burkina Faso & 300 & 340 & $58 \%$ & $43 \%$ \\
\hline
\end{tabular}

Source: SNV 2014 [5]

The investment costs of biogas technology in Table 1 show the variability of cost structures with factors such as construction materials and resource endowments such as skilled labor or technical expertise, locally available materials such as stone and cement, location and size of construction sites with available water supply and adequate livestock dung [13]. Generally, biogas performance assessment shows innovation through research and development could be fertile ground to improve construction materials for biogas development in terms of cost reduction $[2,5]$.

In Ethiopia, initial investment costs of small-scale biogas technology is lower than in neighboring countries such as Kenya, Uganda, and Rwanda. The reason is that the biogas development program in the study area is subsidized and this subsidy scheme was blamed for the poor reputation of biogas technology, so that reliance on high subsidies with the market failure has led to large contributions for little return in the sustainability of the constructed biogas plants. Ethiopia and Uganda constituted the highest (80\%) share in investment cost comparisons in terms of per capita GDP share in 2010. Better in this context is that biogas technology construction costs have declined in Africa from 2010 to 2013. For example, African countries including Ethiopia succeeded in having on average $5.8 \%$ investment cost reduction (see table 1 ).

In conclusion, literature sources on affordability tell us investment costs and affordability factors for low-income households have necessitated a detailed assessment of credit 
access at flexible loan repayment options. Meanwhile, there strong argument on how the combined factors that drive the demand for biogas technology could benefit the low-income households as a means of ensuring the economic wellbeing and help to get clean energy via affordable cost.

\subsection{Biogas and Clean Development}

Biogas technology development is moving at the very slow pace in Africa compared to developing countries in Asia. This slow development is induced by high investment costs, limited access to credit facilities, insufficient supply and the significantly low purchasing power of households [13]. On the other hand, despite abundantly available biogas and other renewable energy sources, and irrespective of high livestock potential, biogas technology utilization is very low in Africa. Such problems are associated with high initial investment costs, inadequate technical skills, and cultural factors [14]. Limited financing resources also hinders biogas technology development in Africa. This makes access to credit critical for low-income households to enable them to take advantage of poverty-reducing opportunities, and to shape economic policy and programs to their benefit [15].

The literature shows that increased income of poor households is directly associated with a preference to invest in renewable energies, including biogas energy. In Africa, for example, high-income households use more efficient energy sources (electricity and gas) while low income households use less efficient energy sources, such as fuelwood and other biomass energy [16]. In Nepal, credit access with reasonable payment period and financing through intermediaries ${ }^{1}$ encourage renewable energy use [17].

Studies on credit financing for development of biogas energy technologies in low-income countries show that access to credit for biogas technology is the highest in Bangladesh (with $86 \%$ coverage). In Indonesia, credit access reached $84 \%$, followed Cambodia at 54\% [2]. Research in India reveals that loan repayment or payback period flexibility (short-term payback) increase adoption of small-scale biogas technology $\left(1\right.$ to $\left.6 \mathrm{~m}^{3}\right)$ [18]. The same study finds that an increase in the capacity of biogas plants, decreases the payback period exponentially such that households invest in biogas plants have on average a 1.6-year payback period (loan installment). Studies also show that poor households can afford new or improved technologies such as biogas if provided with credit financing options. For example, in Nepal the loan installment terms chosen by households contains $36.7 \%$ fixed or equal loan instalment, $41.7 \%$ flexible installment, and $21.7 \%$ no installment at all [16]. Same study revealed that most users prefer to opt for biogas loans for a term of 2-3 years and repay in quarterly instalments.

Availability and substitutability of local resources such as water, bricks, materials (plastics tubes or metal), skilled labor or expertise, less intensive training, and follow up of

1 Credit options when manufacturers or rail distributors acquire loans which are returned to consumers who adopt biogas technology, micro credit, and self-help group financing, which enables access to affordable credit with long time maturity. constructed biogas plants are factors that impact biogas development in low-income communities [5]. In the meantime, biogas technology for cooking requires cultural acceptance, and influenced by livestock ownership, water availability, scarcity, population density, and climate conditions [19].

According to Buysman \& Mol, market models in biogas energy demand decisions related to sustainable self-financed strategies has little success in low-income countries except isolated example such as Cambodian National program (CNBP) started in 2006 [20].

According to Netherlands Development Organization, SNV, 2014, biogas technology development program was started in 2008, in Ethiopia, however, its performance has yet with little success stories [5]. This is because of the shortage of construction materials supply and maintenance personnel, little or no financing options and increased biogas construction costs, as well as inadequate market access [21, 22].

According to Sibanda et al, despite all the constraints, biogas technology has a huge benefit in solving semi-urban sanitation problems and sewer reticulation which may cause chronic epidemic, in Harare, Zimbabwe [23]. They also found that biogas energy has potential for wood savings of 6129 tons /year, paraffin savings of 2.556 tons/year and greenhouse reduction of 980 tons of $\mathrm{CO}_{2}$ equivalent emissions/year which would attract USD2940 from carbon credit sales per year. The Harare research also proves that combined suburb biogas technology is a feasible scenario for producing $7,378 \mathrm{~m}^{3}$ of biogas per day with a production capacity of $384 \mathrm{~kW}$. Such small-scale domestic biogas plants with their applications for cooking, lighting, and bio-slurry can contribute to the global reduction of greenhouse gases (GHG).

In Ethiopia, Gebreegziabher and others, find that biogas adoption in urban areas is a source of clean energy and a means of municipal waste minimization [24].

According to the Netherlands Development Organization, SNV, 2006 base line study, biogas energy can reduce greenhouse gas emission in three basic ways: 1) substitution of the conventional domestic energy source, 2) Modification of traditional waste management practices; and 3) substitution of chemical fertilizer [25].

\subsection{Determinants of Biogas Investment}

In Africa the economic benefits and commercialization of biofuel, specifically biogas technology varies with investment cost estimation, and technical and non-technological barriers [26]. However, technical and non-technical factors both poses problem in biogas energy commercialization in most Sub-Saharan Africa regions [3].

In this region, investment in biogas energy also vary with standardization and quality control. As empirical studies have shown that integrated farming systems with biogas and slurry, financial support to cover initial investment cost, and promotion of multiple use biogas sources would increase widespread adoption of small-scale biogas technology $[2,7]$.

Empirical research in rural Ethiopia shows that biogas technology diffusion varies among households depending on 
age of household head, household size, number of livestock (cattle), firewood collection distance, education of household head, if a household head is female, access to electricity, access to credit, and access to an all-weather road were positively correlated, but access to a marketplace is negatively associated [27].

Similar research by Mengistu et al, in Ofla district of Tigray and Mecha district of Amhara regions in Ethiopia, have reached same finding, except male-headed households were more likely to adopt biogas technology, and include the influence of the education level of the household head, household income, and number of trees planted [28]. In a study conducted by Abadi et al, in Tigray, estimate the relationship between biogas adoption and health status among 200 sample adopter and non-adopter households [29]. Their results reveal that households that adopt small-scaled biogas digesters have significantly lower rates of indoor air pollution and lower expenditure on medication, and spend less time on fuel wood collection than non-adopter households. Similarly, in Aleta Wondo woreda of Sidama region, biogas technology installation among rural households vary with availability of water sources, access to credit, number of cattle, land size, training in masonry, and household income [30]. However, none of these studies address the effect of geographic location (semi-urban and urban context), or access to credit with a flexible repayment schedule (short, medium, and long term) as predictive covariates of investment in biogas technology.

\section{Materials and Methods}

\subsection{Study Area Description}

With a total land size of 1.1 million square kilometers, Ethiopia is twice the size of France and the 10th largest country in Africa. The nation is the second most populous country in Africa after Nigeria, with a population of around 110 million a population growth rate of more than 2.3 percent per annum. The study area, Sidama region is located in Southern Ethiopia and covers a total area of $12,000 \mathrm{~km}^{2}$. The Sidama region is one of the $10^{\text {th }}$ states of Ethiopia. According to the Central Statistics Agency (CSA, 2007), the Sidama region has an estimated population of 4.5 million inhabitants [31].

\subsection{Survey Method}

We prepare a questionnaire comprised of three parts; the first part includes questions on socio- demographic information. The second part comprises questions on household energy uses, available resources in the area, firewood collection, and fuelwood scarcity. The third part includes questions in investment decisions on domestic biogas plants, with a sub-section on credit access with flexible loan repayments (short, medium and long-term) and the amount of funds with respective installment periods. The survey was conducted between August and September 2017, by a team of data collectors trained in the purpose of the research, and enumeration methods.

\subsection{Sampling}

Using stratified random sampling, 298 households in Hawassa city were selected for this study. Covering all kebeles in eight sub-cities, we assume the geographic location and socio-economic classifications as the stratifying factor. A pre-test survey was carried out and revisions were made based from feedback in the field. Finally, the enumerators visited each household and filled in the questionnaires by interviewing the household head. The field survey was supported by the Global Positioning System (GPS) to map the household's geographic location.

\subsection{Econometric Model}

In order to analyze a multiple choice response variable such as investment decisions being conditioned on three loan repayment options for a given household, we estimate a multinomial logit model ${ }^{2}$. The estimation of investment decisions with flexible financing options is the main approach adopted in this study.

We assume the application of the theory of Random Utility Model (RUM) to estimate the economic value of goods and services. The model underlines the consumer's subjective preference that maximizes their satisfaction based on the perceived product or service attributes. The utility derived from investing in or choice technology options is conditional on observable attributes, if the consumer makes choice $j$ in particular, then we assume that $\mathrm{U}_{\mathrm{ij}}$ is the maximum among the $\mathrm{J}$ utilities $[32,33]$. Then we have the utility function;

$$
\mathrm{U}_{\mathrm{ij}}=\mathrm{X}_{\mathrm{ij}} \theta+e i
$$

Empirically, the model is based on the assumption that a household's investment decision related to biogas energy is conditioned on flexible financing options which are independent of one another (since the household has to decide whether they can afford or willing to invest in different longevity periods). The estimation of multiple choice response equations also allows us to account for unobservable household characteristics that may affect investment decisions concerning different loan repayment periods; we only observe the decision to invest in the three options.

These options are, first, short term financing meaning a loan repayment within two years and credit funds of $70 \%$ of initial investment costs of small scale biogas energy. Second, medium term financing, which is a loan repayment in five years with credit funds with $50 \%$ of initial investment costs of biogas scheme. Third, long term financing, representing loan repayment plans in 10 years and with a $30 \%$ credit arrangement that cover initial investment costs. Accordingly, the probability to invest is equal: $\operatorname{Pr}\left(\mathrm{U}_{\mathrm{ij}}>\mathrm{U}_{\mathrm{ik}}\right)$ for all other $\mathrm{k} \neq \mathrm{j}$.

Given individual specific covariates $x i$, the probabilities for $\mathrm{J}$ choices is given by:

2 The multinomial logit model is an extension of the binary logit model. Suppose we face a multiple choice response variable such as loan repayment term choices where the order of the choices does not matter. Such unordered choice model can be motivated by a random utility model. 


$$
\operatorname{Pr}(\mathrm{yi}=\mathrm{j} / \mathrm{xi})=\operatorname{Pr}=\frac{e(X i, \beta j)}{1+\sum_{k=1}^{J} \mathrm{e}(X i, \beta k)}
$$

Where $\mathrm{j}=0,1,2,3 \ldots \ldots, \mathrm{J} ; \beta_{0}=0$

The sum of the $\mathrm{J}+1$ probabilities should equal to one. To avoid indeterminacy, we need only to estimate $\mathrm{J}$ parameters to obtain probabilities for $\mathrm{J}+1$ choices.

The log-likelihood can be derived by defining for each individual $\mathrm{d}=1$ alternative $\mathrm{j}$ individual, $\mathrm{d}_{\mathrm{ij}}$ if is chosen by individual $\mathrm{i}$, and 0 if not, for the $\mathrm{J}+1$ outcomes.

We assume covariates of conditional investment decision in biogas energy are income and sociodemographic and environmental factors.

\section{Description of Survey Data}

\subsection{Characteristics of Socio-economic Survey}

Summary statistics in Table 2 present the sample survey. The average monthly income of the households is 4706.86 ETB and the average family size is 5.6. The majority of household heads are male (59\%), and the average age of household heads is 36 years. The land size on average is 2.15 hectors. $53 \%$ of household heads have informal education while the rest have formal education. Geographically, 33\% of households are semi-urban and $67 \%$ are urban households.

Table 2. Socioeconomic survey $(N=298)$.

\begin{tabular}{lll}
\hline variable & Mean & St. Dev \\
\hline age & 35.78 & 13.80 \\
Household head gender & 0.41 & 0.49 \\
household size & 5.62 & 2.21 \\
income & 4706.86 & 7325.59 \\
Land size & 2.15 & 1.21 \\
Semi-urban & 0.33 & 0.47 \\
Informal education & 0.53 & 0.50 \\
\hline
\end{tabular}

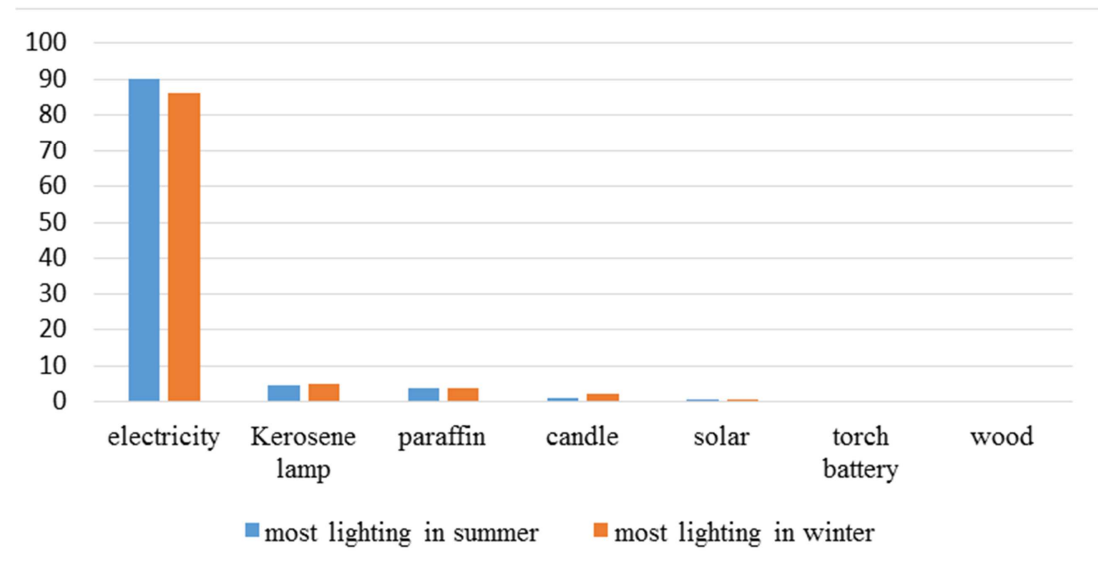

Figure 2. Share of lighting fuel sources in summer and winter, \%.

\subsection{Household Perception on Biogas Technology}

The survey results on biogas technology are presented in table 3, which indicates that $72 \%$ of sample respondents have heard about the biogas technology, while the rest had not. Based on the result, the mass media (television and radio) is found to be the major sources of information (74.81\%)

\subsection{Characteristics of Household Fuel Sources}

Figure 2 shows main fuel sources used for cooking in the summer and winter seasons. In summer, wood takes the main share (48\%), with electricity (35.9\%), and charcoal (17.38\%), while a few respondents $(2.14 \%)$ use leaves in the summer season. In winter there is a nearly equivalent share $(47.59 \%)$ of fuelwood, $35.03 \%$ electricity, and $17.38 \%$ charcoal and very few $(0.54 \%)$ use leaves as fuel sources.

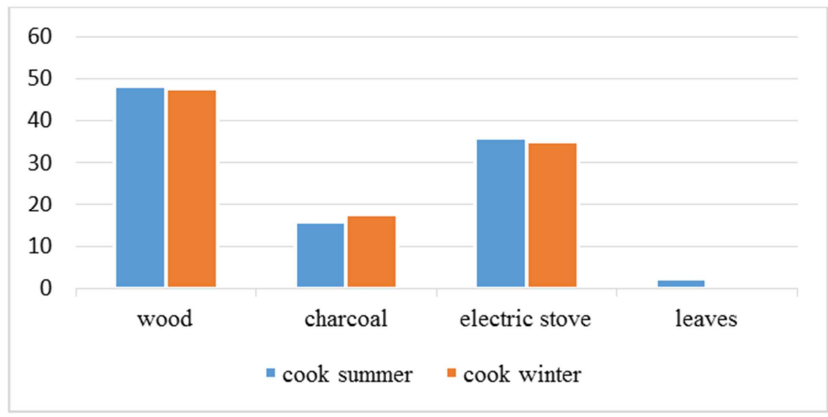

Figure 1. Share of cooking fuel sources in summer and winter, $\%$.

Figure 1 shows main energy sources used for lighting in summer which are $(89.97 \%)$ electricity, kerosene or kuraz (4.61\%), paraffin $(3.79 \%)$, candle $(1.1 \%)$, and solar $(0.54 \%)$.

According to our survey result, the most common fuel source for lighting in winter is electricity which constitutes $(86 \%)$. A small number of householders use kerosene $(4.8 \%)$, paraffin $(3.77 \%)$, candles $(2.16 \%)$, solar $(0.81 \%)$, torch batteries $(0.27 \%)$, and wood $(0.27 \%)$.

In both seasons many householders use electricity as a primary lighting source. The differences in lighting fuel sources in terms of electricity are about 3\% lower in the winter. 
statement and $15.41 \%$ disagreed with biogas technology promotion.

Table 3. Description of households 'perception of biogas technology.

\begin{tabular}{lll}
\hline Questions & response options & Percent (\%) \\
\hline Have you ever heard about the biogas technology? & yes & 72.16 \\
& biogas promotion & 2.96 \\
& extension workers & 5.93 \\
How did you get information on biogas technology for the 1st time? & mass-media & 74.81 \\
& previous users & 10.74 \\
& researchers & 4.44 \\
& school & 82.73 \\
What do you think about biogas technology as alternative energy source? & appropriate & 17.27 \\
& not appropriate & 30.82 \\
Do you agree biogas technology to be promoted? & strongly agree & 49.85 \\
& agree & 3.02 \\
\end{tabular}

\subsection{Wastewater Systems}

Figure 3 presents household characteristics in terms of wastewater management systems. Our survey results show that householders connected to a home sewage system or who had their own septic tank constituted $21 \%$. The simple majority $(37 \%)$ of householder's discharge wastewater directly to a drainage ditch or land, while $36 \%$ of householders discharge wastewater directly to prepared pits within a compound. Very few respondents $(4.8 \%)$ use other means to discharge wastewater from the house.

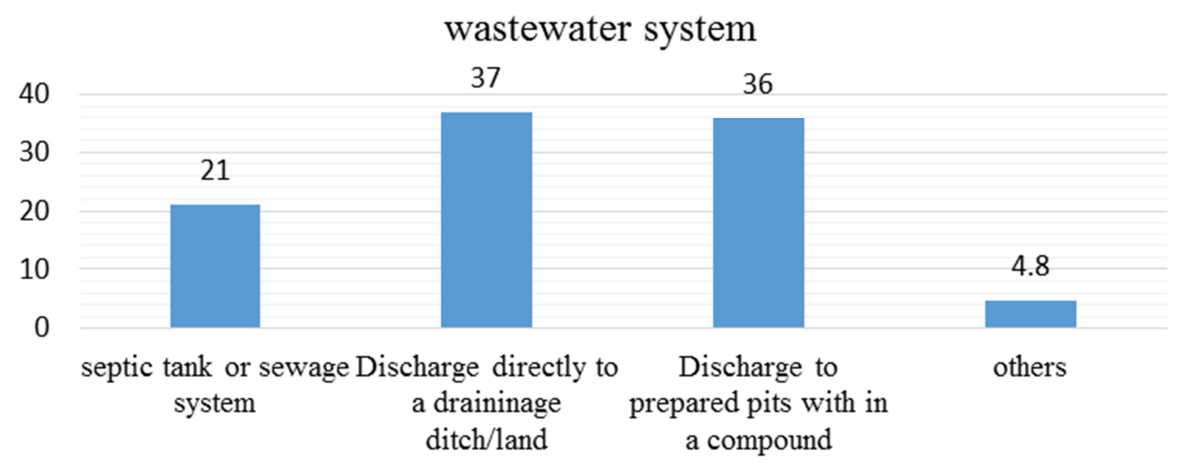

Figure 3. Percentage distribution of respondent's wastewater system.

\subsection{Availability of Water and Fuelwood Sources}

Availability and access to domestic water resources, firewood for cooking, and grazing land for fodder are the most important external factors determining household fuel choices. Three response options were available to respondents; (1) Readily available (2) available in short supply (3) Not available.

water sources

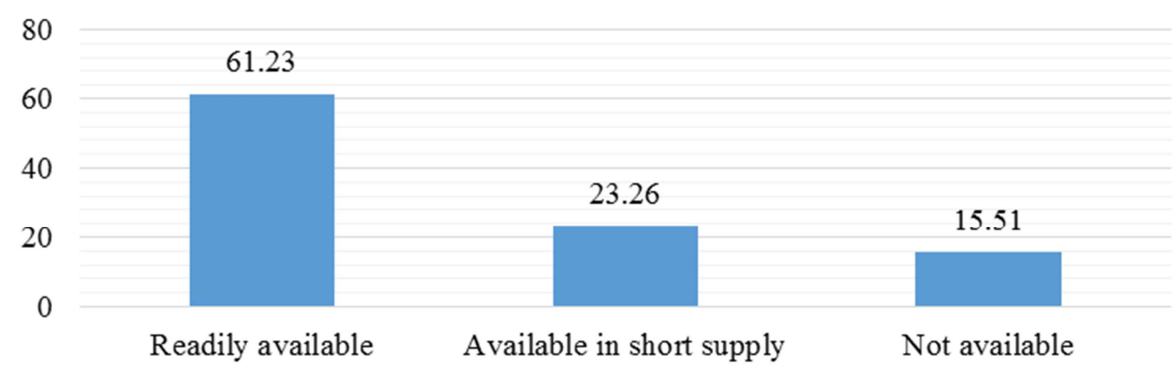

Figure 4. Percentage distribution of water sources.

Figure 4 shows, $61.23 \%$ of respondent's have readily available domestic water sources, $23.26 \%$ have domestic water sources available but in short supply, and $15.51 \%$ of respondents do not have domestic water sources in their area. 


\section{Fuelwood source}

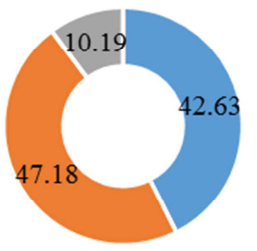

" Readlily available " Available in short supply " Not avialable
Figure 5 shows $42.63 \%$ of households in the study area have a readily available fuelwood source, $47.18 \%$ have available fuelwood in short supply and $10.19 \%$ of them have no available fuelwood source.

\subsection{Willingness to Invest in Biogas Energy with Credit Access at Flexible Financing $(\mathrm{N}=298)$}

Household's willingness to invest in biogas energy if they are provided with a subsidy from the government or credit schemes is presented in the following loan repayment schedule.

Figure 5. Percentage distribution of fuelwood sources.

Table 4. Investment in biogas energy with credit access in flexible financing.

\begin{tabular}{|c|c|c|c|c|}
\hline Time & Loan repayment options & Credit amount & Initial investment cost (Birr) & percentage of respondents \\
\hline 2 years & Short-term & $70 \%$ & 14000 & 14.1 \\
\hline 5 years & Medium-term & $50 \%$ & 14000 & 24.47 \\
\hline 10 years & Long-term & $30 \%$ & 1400 & 61.44 \\
\hline
\end{tabular}

Table 4 shows the demand for biogas energy accompanied by credit access with flexible loan installments. $14.1 \%$ of households were willing to invest with short-term loan repayment plans at the corresponding outstanding amount of $70 \%$ of initial investment cost. $24.47 \%$ of households were willing to invest with medium term loan installments with credit funds of $50 \%$ of initial investment costs. The majority of households $(61.4 \%)$ were willing to invest with a long-term loan installment plan with the funding option $30 \%$ of initial investment cost.

Table 5. Independent variable, definition, and expected sign.

\begin{tabular}{lll}
\hline Variable & Definition & Expected sign \\
\hline livestock & Livestock $=1$ if f household own at least 4 cows 0 otherwise \\
Land size & Household Land holdings in square meter & + \\
Waste water system & Household water system connected to waste disposal \\
Male & male=1 if gender of respondent's head 0 otherwise & + \\
Alternative fuel source & Knowledge of alternative fuel source other than biomass & + \\
Informal education & Informal education of household head & $+/-$ \\
Formal education & Formal education of household head & $+/-$ \\
\hline
\end{tabular}

\section{Estimation Results}

The econometric results from multinational model estimation presents conditional covariates that explain investment in biogas technology are shown in Table 6. We undertook thorough diagnosis tests using post-estimation tools that can be used to help interpret model results. We did likelihood ratio tests that provide an alternative method in testing sets of coefficients, and marginal predictions for multiple variables (responses).

Table 6. Econometric results from multinomial logit estimates $(n=298)$.

\begin{tabular}{lll}
\hline \multirow{2}{*}{ Variables } & Loan repayment schedule & \\
\cline { 2 - 3 } & Short-term & Medium-term \\
\hline livestock & $0.629(0.456)$ & $0.581(0.358)$ \\
Land size & $-0.339^{* *}(0.166)$ & $0.101(0.152)$ \\
Waste water system & $1.110^{* *}(0536)$ & $0.152^{* *}(0.421)$ \\
Male is household head & $-0.965 * *(0.454)$ & $-0.563 *(0.332)$ \\
Alternative fuel source & $-1.741^{* *}(0.467)$ & $-0.344(0.356)$ \\
Informal education & $2.338^{* *}(0.685)$ & $1.100(0.759)$ \\
Formal education & $1.041 * *(0.461)$ & $1.040 * *(0.349)$ \\
cons & $-0.850 *(0.506)$ & $-1.846 * * *(0.525)$ \\
\hline
\end{tabular}

Notes: SE values in parentheses. $* P<0.10, * * p<0.05, * * * p<0.01$ represent significance at $10 \%, 5 \%$ and $1 \%$ level, respectively.

Some of the covariates included in this paper were omitted, and only statistically significant ones with predicted probabilities are considered in further interpretation, discussion and policy recommendations.

Among the socio-economic variables, male household head and investment in biogas are indirectly correlated and significant at a 5 percent significance level in relation to the short and medium term repayment schedule relative to long term. Informal education has a positive and direct effect on decision to invest in biogas energy with the short-term loan 
repayment schedule at a 5 percent significance level. However, formal education has an indirect effect on investment with a short or medium term repayment schedule relative to a long term repayment schedule, at a 5 percent significance level. The coefficient estimate of a waste water system has a positive and significant association with investment in biogas energy, at 5 percent significant level, while access to alternative fuel sources and land size are negatively associated with investment in biogas energy conditioned on a shorter loan repayment schedule. (See table 7 )

In contrast, the difference in household size, age of household head, marital status, family relationship, occupation, geographic location (semi-urban vs urban), ethnicity, and religion were not statistically significant and not included in the interpretation of estimation results.

Table 7. Marginal effects from multinomial logit model $(n=298)$.

\begin{tabular}{llll}
\hline \multirow{2}{*}{ variable $\mid$} & \multicolumn{2}{l}{ Loan repayment schedule } & Long term \\
\cline { 2 - 4 } & Short term & Medium term & $-.062(.057)$ \\
\hline Livestock & $.0002(.029)$ & $.062(.050)$ & $008(.026)$ \\
Land size & $-.0267 * *(.012)$ & $.018(.023)$ & $-.256 * * *(.087)$ \\
Waste water system & $.049(.047)$ & $.207 * *(.083)$ & $.117 * * *(.0562)$ \\
Male is household head & $-.055(.030)$ & $-.062(.049)$ & $.170 * * *(.065)$ \\
Alternative fuel source & $-.148 *(.045)$ & $-.022(.055)$ & $-.378 * * *(.133)$ \\
Informal education & $.280 * *(.137)$ & $.097(.143)$ & $.149 * * *(.065)$ \\
Formal education & $.061(.042)$ & & $-.210 * * *(.070)$ \\
\hline
\end{tabular}

Notes: SE values in parentheses. $* P<0.10, * * p<0.05, * * * p<0.01$.

Average marginal effects of independent variables are shown in the table 7.

The marginal effect of a male household head increases the probability of investing in biogas energy with a long-term loan repayment plan by 0.11 , relative to short and medium term plans. This is in line with the results from the literature on the role of gender in investment in biogas technology that shows heterogeneity across regions in Ethiopia. For example, in Tigray region of Ethiopia, female-headed households are more likely to invest in biogas technology [27]. In contrast, in Amhara region, male-headed households are more likely to invest in biogas energy [28]. It is also consistent with the study result in Uganda that female-headed respondents are less likely to invest in biogas technology than their male counterparts [32].

A household head having informal education increases the probability of investing in biogas energy with a short-term loan repayment schedule by a factor 0.28 . However, with the long-term repayment, a household head having informal education reduces their willingness to invest in biogas energy by a factor 0.37 . The marginal effect of formal education is more likely increase the household's willingness to invest in biogas energy with the medium term loan repayment schedule by 0.149 compared to short and long-term options. However, the marginal effect of a household head having formal education in the long-term repayment option reduces the probability of the household investing in biogas energy by 0.21 compared to the short and medium options. This is consistent with previous study results that show a positive association between education and investment in biogas technology [27].

The marginal effect of the economic variable land size reduces the probability of investing in biogas energy in the short-term loan repayment period, relative to medium and long-term options. This means a one-unit increase in land size in hectares is associated with a 0.026 decrease in the relative marginal effects of being willing to invest in biogas technology with the short-term repayment plan than the long-term option. Many empirical studies in related regions agreed that increasing land holdings had a decreasing effect on investment in biogas energy [30, 32].

The relative marginal effect of household's being connected to a waste water system increases the probability of investing in biogas energy in the medium-term loan repayment schedule by a factor of 0.2 , compared to short and long terms. However, the effect of a waste water system reduces the probability of investing in biogas energy by 0.25 in the long-term loan repayment option compared to the short and medium schedules. The result is consistent with findings from Ghana that a novel septic tank design (up flow domestic septic tank) can help to recover biogas as energy and treat domestic sewage [34]. Connecting waste water systems to biogas digester also shown to be a feasible sanitation solution in urban slums in Bwaise III, Uganda [35].

The marginal estimates of alternative fuel source (access to fuelwood and other biomass) reduce the probability of households investing in biogas energy by 0.14 in the short term repayment option, relative to long and medium term options. In this regard, previous study results [27] reveal access to fuelwood in the nearest market is negatively associated with the adoption of biogas energy in rural Tigray, North Ethiopia. However, the effect of access to alternative fuel is more likely to increase the probability to invest in biogas energy in the long term by 0.17 compared to the short and medium term options. Thus, the association between long term repayment options and access to other fuel sources is also consistent with the result of a positive net present value from investing in biogas technology compared to householders collecting their own energy sources. This is in line with the study findings of Oromia and South region of Ethiopia that reveal the benefits of biogas energy such as bio-slurry use for agriculture production, time and energy saved by women and children [36]. 


\section{Discussion}

This paper, examines the determinants of investment in small-scale biogas energy, conditioned on credit access with flexible loan repayment options. The covariates that have a significant effect on investment decision were discussed as follows. Our results reveal that, with short-term loan repayment options with high credit rate $(70 \%$ of investment cost) women are more likely to invest in biogas technology. Practically, in the study area, women's participation in investment in biogas technology and the share of a loan extended to them is low (only 10\%) in Ethiopia [2]. This is the lowest of the regional loan share for women in African countries. For example, the loan share of women in Rwanda is $25-30 \%$, and in Kenya, the loan share of women reaches to $90 \%$. The implication is that if the loan share of women increases significantly there will be a high probability of investment in biogas technology or renewable sources. If they can afford to pay the required investment cost and have autonomous decision-making powers women will benefit from biogas technology in terms of reduced health risks, and time and energy saved. Biogas technology use also increase convenience and reduces hardships related to fuelwood collection by women and children [37]. Household landholding (size) does not affect investment in biogas energy with short-term loan instalments. It holds for medium and long-term loan instalments. In the short-term credit option, those households that own a large area of land can simply get fuel for cooking from their own land and therefore do not want to invest in biogas energy. Instead, they invest in biogas energy in the long-term credit option, as they are not certain about future fuel sources. Moreover, the inverse relationship between the probability of investing in biogas technology with short-term loan repayment options and large land holdings may indicate the minimal effort of promotion and awareness creation around biogas. Households are ill-informed on the benefits of improved fuel sources, such as the role of bio-slurry as a fertilizer source (biogas digester bi-product) that could increase agricultural efficiency and ensure clean production of agricultural outputs. The result is consistent with other findings that land size and adoption of biogas energy are inversely related among rural households [30]. The research findings regarding livestock ownership reveal that households that possess more cattle and other livestock are more likely to invest in biogas energy since they will have enough substrate for plant operation. An increase in the number of livestock, particularly, cattle has the same magnitude of increasing the probability of investing in biogas energy. However, livestock ownership may not be the only determinant, as there is the presence of other wastes that might generate biogas energy, specifically in semi-urban areas. The relationship between formal education and investment in biogas energy is more influential in the short and medium-term loan instalment scenarios than the long term option, while informal education has a modest influence for biogas energy in the medium-term instalment option relative to the long term option.
The covariate waste water system (septic tank) connected to a biogas reactor is beneficial to produce clean biogas energy. Thus, planning for direct conversion of domestic waste water systems or septic tanks to a biogas digester is simple and can be a potentially feasible and sustainable sanitation solution in urban or semi-urban areas. Both short and medium term credit financing options will increase investment in biogas energy among households connected to a waste water system.

The biogas demand with credit access with a short-term repayment option has less effect than in the long-term option if abundant alternative fuelwood sources are available in the locality. In the short-run option, householders have no experience of fuelwood scarcity, and it is not an immediate subject that needs to be dealt with. Nevertheless, investment in biogas energy in the long-run option depends on the expected present value of initial and operating costs with competitive borrowings (loans) if there is uncertainty about the availability of fuelwood in the future. This is consistent with the demand theory applied to long-run demand for electricity consumption conditioned on appliance holdings [38] that the association between investments in improved technology and competitive borrowings with expectations with discount rate assumptions.

\section{Conclusion}

The main findings of this study reveals that women household heads are more likely willing to invest in biogas technology in a short-term loan repayment options with credit funds of $70 \%$ initial investment costs. Another finding is that households with large land holdings and that have alternative fuel sources prefer long-term loan repayment options with lower credit funds of $30 \%$ initial investment cost. Further, education has a direct effect on investment decision. Households with a head with informal education were more likely to invest in biogas technology at medium-term loan option with credit funds amounting to $50 \%$ of initial investment cost. On the other hand, households with heads with formal education were more likely to invest in biogas technology at short-term and medium-term loan options of $70 \%$ and $50 \%$ respectively. An increasing number of livestock owners were more likely to invest in biogas technology with short-term loan options with credit funds of $70 \%$ of initial investment costs. For urban households connected to home sewage systems, investment in biogas varies with short and medium loan financing options, given $70 \%$ and $50 \%$ of credit funding respectively.

To sum up, the study findings suggest that flexible credit financing access should take into account gender balanced credit shares, specifically, measures for women may increase adoption of sustainable, clean and biogas energy technologies among low-income households. Education and training related to the benefits of biogas technology should be prioritised presenting bio-slurry as a natural fertilizer, and sanitary solution in urban and semi-urban areas. Policymakers can also create demand for biogas from households with large land holdings and that have alternative fuel sources through offering credit funding with flexible financing along with 
user-centred benefit valuation and further promotions.

\section{Acknowledgements}

The Author would like to acknowledge Charles University Environment Centre and GEMCLIME project for supporting data analysis and article write-up.

\section{References}

[1] Africa progress report, 2015. Seizing Africa's Energy and Climate opportunities, Power People Planet; African Progress Panel.

[2] Mwirigi, J., Balana, B. B., Mugisha, J., Walekhwa, P., Melamu, R., Nakami, S., \& Makenzi, P. (2014). Socio-economic hurdles to widespread adoption of small-scale biogas digesters in Sub-Saharan Africa: A review. Biomass and bioenergy, 70, $17-25$.

[3] Parawira, W. (2009). Biogas technology in sub-Saharan Africa: status, prospects and constraints. Reviews in Environmental Science and Bio/Technology, 8 (2), 187-200. Purnama Alamsyah, K. Analysis of Biogas Financing using causal Loop Diagram in Lembang Area, West Java, Indonesia.

[4] UNDP: World energy assessment overview: Sustainable development goals. New York, USA: United Nations Development Program; 2004 updates.

[5] SNV. (2014). An Assessment of Small-Scale Bio digester Programmes in the Developing World: The SNV and Hivos Approach.

[6] Gautam, R., Baralb, S., and Herat S. (2009). "Biogas as a sustainable energy source in Nepal: Present status and future challenges". Renewable and Sustainable Energy Reviews 13, p. 248-252.

[7] Katuwal, H. and Bohara, A. K. (2009). "Biogas: A promising renewable technology and its impact on rural households in Nepal". Renewable and Sustainable Energy Reviews 13, p. 2668-2674.

[8] Amigun, B., \& Von Blottnitz, H. (2009). Capital cost prediction for biogas installations in Africa: Lang factor approach. Environmental Progress \& Sustainable Energy: An Official Publication of the American Institute of Chemical Engineers, 28 (1), 134-142.

[9] Amigun, B., Sigamoney, R., \& von Blottnitz, H. (2008). Commercialization of biofuel industry in Africa: a review. Renewable and sustainable energy reviews, 12 (3), 690-711.

[10] Mengistu, M. G., Simane, B., Eshete, G., \& Workneh, T. S. (2015). A review on biogas technology and its contributions to sustainable rural livelihood in Ethiopia. Renewable and Sustainable Energy Reviews, 48, 306-316.

[11] Biogas inventory report (2017), South Nations Nationalities and People Region Mines and Energy agency, Ethiopia.

[12] Barnes, D. F., Krutilla, K., \& Hyde, W. (2005). The urban household energy transition. Resources for the Future Press, Washington, DC.

[13] Ghimire, P. C. (2013). SNV supported domestic biogas programmes in Asia and Africa. Renewable Energy, 49, 90-94.
[14] Mshandete, A. M., \& Parawira, W. (2009). Biogas technology research in selected sub-Saharan African countries-A review. African Journal of Biotechnology, 8 (2).

[15] Kanbur, R., \& Squire, L. (2001). The evolution of thinking about poverty: exploring the interactions. Frontiers of development economics-The future perspective, 183-226.

[16] Panjwani, Anja, and Elizabeth Cecelski. "Major Activities and Actors in Energy, Poverty and Gender." (2002).

[17] Center for Micro Finance (CMF), (2013). Study on the impact of credit on the installation of Biogas Plant, Final report. National rural renewable energy program (NRREP), Alternative Energy Promotion Center, Ministry of Environment science and Technology, Khumaltar, Lalitpur, Nepal.

[18] Singh, K. J., \& Sooch, S. S. (2004). Comparative study of economics of different models of family size biogas plants for state of Punjab, India. Energy Conversion and Management, 45 (9-10), 1329-1341.

[19] Sagar, A. D., \& Kartha, S. (2007). Bioenergy and sustainable development? Annu. Rev. Environ. Resour, 32, 131-167.

[20] Buysman, E., \& Mol, A. P. (2013). Market-based biogas sector development in least developed countries - the case of Cambodia. Energy Policy, 63, 44-51. Cecelski, E. (2002). Enabling equitable access to rural electrification: current thinking and major activities in energy, poverty and gender.

[21] Landi, M., Sovacool, B. K., \& Eidsness, J. (2013). Cooking with gas: policy lessons from Rwanda's National Domestic Biogas Program (NDBP). Energy for Sustainable Development, 17 (4), 347-356.

[22] Mulinda, C., Hu, Q., \& Pan, K. (2013). Dissemination and problems of African biogas technology. Energy and Power Engineering, 5 (08), 506.

[23] Sibanda, G., Musademba, D., Chihobo, H. C., \& Zanamwe, L. (2013). A Feasibility Study of Biogas Technology to Solving Peri-urban Sanitation Problems in Developing Countries. A Case for Harare, Zimbabwe. International Journal of Renewable Energy Development, 2 (2), 97-104.

[24] Gebreegziabher, Z., Naik, L., Melamu, R., \& Balana, B. B. (2014). Prospects and challenges for urban application of biogas installations in Sub-Saharan Africa. Biomass and bioenergy, 70, 130-140.

[25] SNV, 2006. Report on the feasibility study of a national programme for domestic biogas in Ethiopia.

[26] Kamp, L. M., \& Forn, E. B. (2016). Ethiopia' s emerging domestic biogas sector: status, bottlenecks and drivers. Renewable and Sustainable Energy Reviews, 60, 475-488.

[27] Kelebe, H. E., Ayimut, K. M., Berhe, G. H., \& Hintsa, K. (2017). Determinants for adoption decision of small-scale biogas technology by rural households in Tigray, Ethiopia. Energy Economics, 66, 272-278.

[28] Mengistu, M. G., Simane, B., Eshete, G., \& Workneh, T. S. (2016). Factors affecting households' decisions in biogas technology adoption, the case of Ofla and Mecha Districts, northern Ethiopia. Renewable Energy, 93, 215-227.

[29] Abadi, N., Gebrehiwot, K., Techane, A., \& Nerea, H. (2017). Links between biogas technology adoption and health status of households in rural Tigray, Northern Ethiopia. Energy Policy, 101, 284-292. 
[30] Shegenu, G., \& Seyoum, A. (2018). Determinant of Biogas Technology Adoption and Its Implication on Environmental Sustainability: A Case of Aleta wondo Woreda, Sidama Zone, South Ethiopia. Global Journal of Human-Social Science Research.

[31] Ethiopian Central statistical agency 2007.

[32] Walekhwa, P. N., Mugisha, J., \& Drake, L. (2009). Biogas energy from family-sized digesters in Uganda: critical factors and policy implications. Energy policy, 37 (7), 2754-2762.

[33] Lancaster, K. J. (1966). A new approach to consumer theory. Journal of political economy, 74 (2), 132-157.

[34] Mawufemo, M. (2015). Design of Biogas Septic tanks for treating domestic sewage (Doctoral dissertation).

[35] Katukiza, A. Y., Ronteltap, M., Oleja, A., Niwagaba, C. B., Kansiime, F., \& Lens, P. N. (2010). Selection of sustainable sanitation technologies for urban slums-A case of Bwaise III in Kampala, Uganda. Science of the total environment, 409 (1), 52-62.

[36] Gwavuya, S. G., Abele, S., Barfuss, I., Zeller, M., \& Müller, J. (2012). Household energy economics in rural Ethiopia: A cost-benefit analysis of biogas energy. Renewable Energy, 48, 202-209.

[37] Al Tanjil, H., Akter, S., Chowdhury, M. S., Jabin, S. M., Mintu, A. H., Ahmed, M. T., \& Hossain, M. S. (2019). Biogas as an Alternative Energy Source in Rural Areas and Public Awareness: A Case Study in Jessore District. Journal of Energy and Natural Resources, 8 (1), 12.

[38] McFadden, D. (1977). Quantitative methods for analyzing travel behavior of individuals: some recent developments. Berkeley: Institute of Transportation Studies, University of California. 